\title{
DEVINE, Jane and EFFER-SIDER, Francine. Going Beyond Google: The invisible web in learning and teaching. London: Facet Publishing. 2009. 156 pages. ISBN 9781856046589 . $£ 44.95$.
}

For all those who realised that there is more information available than just that provided by a Google search - that of the invisible web - this book offers a range a practical tools and methods for information professionals to engage with students to enhance their searching ability - whilst enhancing the overall skill set of the reader.

The gauntlet has been thrown down and this book has joined the ranks of those trying to stem the growing tunnel vision fostered through Google searching. Generations of users merrily use keyword searching in Google and will often find what they need in the generated results - this is not necessarily a problem for many, it depends on the type of information they are looking for.

For those trying to foster and encourage a deeper understanding of information in a range of contexts for serious research, this publication provides practical tools and techniques which will assist the information professional in their endeavours.

Jane Devine (Chief Librarian) and Francine Egger-Sider (Coordinator of Technical Services) are both at LaGuardia Community College, which is part of City University of New York. Two previous articles by the authors concerning the implications of Google on the library [published in 2004 and 2005] have obviously developed the concepts covered in this publication. The book is split into three main sections which first educate the reader about the differences between the visible and invisible web; then develop the understanding into how to utilise the contents of the invisible web; and conclude with work which is opening up access to the invisible web.

The publication is well referenced and obviously student focused with many useful tips regarding the most common myths and how to dispel these at the outset with a range of well designed graphics and background material. As with any book which makes extensive reference to current web resources, it is possible that this may date some of the content due to the rapid pace of development within this area - a tool which searches in a particular way in 2009 is likely to revise its heuristics during 2010 - this would particularly be true of Google which frequently updates its functionality.

The book often shows its implicit American style in a number of key areas which readers should be aware of. The cover hints of the use of the invisible web in the VLE product Blackboard which has prevalent use in America but is certainly not universal in the world of virtual environments. With the explicit naming of this tool, I was expecting some key functionality to be highlighted and was disappointed to be told to raise the topic of the invisible web in discussion boards or make external links to alternative web resources - something which any basic VLE is capable of doing. Of more concern was the significant focus on research and developments based in the U.S. rather than worldwide. For example, JISC's only reference was to the 2007 study on the Information Behaviour of the Researcher of the Future, and yet there is extensive work in progress to make better access for Institutional Repositories which 
JISC has funded from 2006 - a key development in invisible web searching. One of the particular projects (UK Institutional Repository Search - www.intute.ac.uk/irs) has made progress in areas which would significantly benefit the serious researcher with searching techniques not currently capable in Google Scholar.

After reading the book I was certainly far more knowledgeable about the invisible web and techniques to maximise its use - and will be trying out some of the links provided in my own research. Whilst I'm aware that the publication will not have covered all activity in the area and will already be aging - it currently provides an excellent resource for information professionals who are attempting to guide the serious researchers of the future.

\section{Rob Howe}

Head of Learning Technology and Media Development The University of Northampton

Rob.Howe@northampton.ac.uk 